\title{
Co-infection of Haemonchus contortus and Trichostrongylus spp. among livestock in Malaysia as revealed by amplification and sequencing of the internal transcribed spacer II DNA region
}

Tiong K Tan ${ }^{1}$, Chandrawathani Panchadcharam², Van L Low ${ }^{3}$, Soo C Lee ${ }^{1}$, Romano Ngui ${ }^{1}$, Reuben SK Sharma ${ }^{4}$ and Yvonne AL Lim ${ }^{1 *}$

\begin{abstract}
Background: Haemonchus contortus and Trichostrongylus spp. are reported to be the most prevalent and highly pathogenic parasites in livestock, particularly in small ruminants. However, the routine conventional tool used in Malaysia could not differentiate the species accurately and therefore limiting the understanding of the co-infections between these two genera among livestock in Malaysia. This study is the first attempt to identify the strongylids of veterinary importance in Malaysia (i.e., H. contortus and Trichostrongylus spp.) by amplification and sequencing of the Internal Transcribed Spacer II DNA region.

Results: Overall, 118 (cattle: 11 of 98 or 11.2\%; deer: 4 of 70 or 5.7\%; goats: 99 of 157 or 63.1\%; swine: 4 of 91 or $4.4 \%$ ) out of the 416 collected fecal samples were microscopy positive with strongylid infection. The PCR and sequencing results demonstrated that 93 samples (1 or $25.0 \%$ of deer; 92 or $92.9 \%$ of goats) contained $\mathrm{H}$. contortus. In addition, Trichostrongylus colubriformis was observed in 75 (75.8\% of 99) of strongylid infected goats and Trichostrongylus axei in 4 (4.0\%) of 99 goats and 2 (50.0\%) of 4 deer. Based on the molecular results, co-infection of H. contortus and Trichostrongylus spp. (H. contortus $+T$. colubriformis denoted as HTC; H. contortus $+T$. axei denoted as HTA) were only found in goats. Specifically, HTC co-infections have higher rate (71 or $45.2 \%$ of 157 ) compared to HTA co-infections (3 or $1.9 \%$ of 157 ).

Conclusions: The present study is the first molecular identification of strongylid species among livestock in Malaysia which is essential towards a better knowledge of the epidemiology of gastro-intestinal parasitic infection among livestock in the country. Furthermore, a more comprehensive or nationwide molecular-based study on gastro-intestinal parasites in livestock should be carried out in the future, given that molecular tools could assist in improving diagnosis of veterinary parasitology in Malaysia due to its high sensitivity and accuracy.
\end{abstract}

Keywords: Strongylid, Haemonchus contortus, Trichostrongylus, Infection rate, Livestock, Co-infection, Second internal transcribed spacer (ITS2) of ribosomal DNA

\footnotetext{
* Correspondence: limailian@um.edu.my

'Department of Parasitology, Faculty of Medicine, University of Malaya, 50603

Kuala Lumpur, Malaysia

Full list of author information is available at the end of the article
} 


\section{Background}

Nematode parasites commonly known as strongylids belonging to the order Strongylida and superfamily Trichostrongyloidea significantly affect the health of livestock [1]. Among these strongylid species, Haemonchus contortus and Trichostrongylus spp. are reported to be the most prevalent and highly pathogenic in livestock, particularly in small ruminants. It is indisputable that $H$. contortus is the most notorious parasite in livestock (i.e., ruminants) due to its biotic potential and blood sucking ability [2]. Haemonchus contortus infection (i.e., haemonchosis) may exhibit clinical signs such as anemia, followed by lack of appetite, lethargy, loss of weight, dehydration, oedema and death as a consequence of the disease [2-5]. As compared to $H$. contortus, Trichostrongylus infection may show milder clinical signs, which may result in inappetence, weight loss, poor body condition, emaciation, diarrhea, hypoproteinaemia and death in the case of heavy infection, particularly in malnourished animals $[5,6]$.

In animal treatment management, species identification of strongylid is often deemed unnecessary; given that drug treatment is usually similar for the different species. Nonetheless, strongylid species identification is crucial in obtaining a greater understanding of the epidemiology, population biology and anthelmintic treatment efficacy, all of which are essential factors for formulating effective parasite control strategies. It is important to emphasize that this information is rarely obtained from conventional diagnostic technique. Strongylid species can only be successfully identified via advanced tools such as molecular techniques. It is important then to know this fact as it is possible that an individual animal could be susceptible to more than one strongylid species when several species are circulating in a farm pasture $[7,8]$. The occurrence of mixed infections may pose a serious problem as they could aggravate the health consequences of the infected animal.

In Malaysia, detection of ova is routinely performed by a floatation principle and observation under a light microscope in veterinary diagnostic laboratories, namely, universities and government agencies (i.e., Department of Veterinary Services or DVS, Malaysia). Although this technique enables a wide range of parasite detection, information of genus and species cannot be easily deciphered. Given that each genus of strongylid has a certain range of egg sizes, the overlapping sizes make it more challenging to pinpoint its genus especially for inexperienced staff. Although fecal culture is another technique for strongylid identification by defining the specific genus characteristics at larval stage, this method is unfortunately time-consuming and requires technical expertise. Furthermore, the accuracy of identification may be questionable and it is impossible to identify the strongylid up to species level.
The utilization of molecular tools such as PCR and DNA sequencing has enabled the accurate identification of parasite species [9]. These advanced techniques are highly sensitive, providing highly accurate identification of strongylids up to species level. Starting from 1990, the Internal Transcribed Spacer (ITS) of nuclear ribosomal DNA (i.e., Second Internal Transcribed Spacer or ITS2) has been developed as a reliable genetic marker in strongylid species identification [9-13] due to its high interspecific sequence divergence and intraspecific sequence homogeneity $[14,15]$. Among these studies, Bott et al. [12] developed a real time-PCR coupled with melting curve analysis based on the ITS2 of ribosomal DNA for the improvement in veterinary parasitology diagnosis on seven common strongylid parasites, namely $H$. contortus, Trichostrongylus spp., Teladorsagia circumcincta, Cooperia oncophora, Chabertia ovina, Oesophagostomum columbianum and Oesophagostomum venolosum in small ruminants.

In the present study, species specific primers from Bott et al. [12] were applied to amplify ITS2 DNA region of $H$. contortus and Trichostrongylus spp. from microscopy positive fecal samples of Malaysian livestock. This study is the first attempt to accurately identify the Stronglyes of veterinary importance in Malaysia (i.e., H. contortus and Trichostrongylus spp.) by molecular methods. The application of advanced molecular tools in determining the specific identity of strongylid species will provide complementary evidence to the microscopy detection of eggs and larvae.

\section{Results}

A total of 416 rectal fecal samples from four types of livestock (i.e., 98 cattle; 70 deer, 157 goats and 91 swine) were examined (Table 1). Among the examined samples, 118 (11 or $11.2 \%$ of cattle; 4 or $5.7 \%$ of deer; 99 or $63.1 \%$ of goats; 4 or $4.4 \%$ of swine) were microscopically positive for strongylid parasites and these parasites were subsequently subjected to molecular identification of H.contortus and Trichostrongylus spp.

ITS2 DNA region of $H$. contortus was amplified in 94 (79.7\% of 118) individuals, consisting of 93 isolates from goats (93 of 99 or $93.9 \%$ ) and one from deer (1 of 4 or 25\%) (Table 1). Of these, 92 amplicons were successfully sequenced and represented by two distinct sequence types [GenBank accession numbers KF204571 and KF204572]. Neighbour-Joining analysis revealed that both sequences were clustered with $H$. contortus sequences available from GenBank (99-100\% similarity) and apparently differed from its closely related species $H$. placei. As for Trichostrongylus spp. detection, a total 81 amplicons were amplified, comprising 79 goats $(79.8 \%$ of 99$)$ and two deer (50.0\% of 4$)$. Of these, all amplicons were successfully sequenced revealing five sequence types [GenBank accession numbers KF204573 to KF204577]. Neighbor-Joining 
Table 1 Number of strongylid positive samples by microscopy and PCR from different type of livestock

\begin{tabular}{|c|c|c|c|c|c|c|c|}
\hline \multirow[t]{3}{*}{ Livestock } & \multirow[t]{3}{*}{ No. examined } & \multirow{2}{*}{\multicolumn{2}{|c|}{$\begin{array}{l}\text { Microscopy } \\
\text { positive }\end{array}$}} & \multicolumn{4}{|c|}{ PCR positive } \\
\hline & & & & \multicolumn{2}{|c|}{ Haemonchus contortus } & \multicolumn{2}{|c|}{ Trichostrongylus spp. } \\
\hline & & No. & $\%$ & No. & $\%$ & No. & $\%$ \\
\hline Cattle & 98 & 11 & 11.2 & 0 & 0 & 0 & 0 \\
\hline Deer & 70 & 4 & 5.7 & 1 & 25.0 & 2 & 50.0 \\
\hline Goat & 157 & 99 & 63.1 & 93 & 93.9 & 79 & 79.8 \\
\hline Swine & 91 & 4 & 4.4 & 0 & 0 & 0 & 0 \\
\hline Total & 416 & 118 & 28.4 & 94 & 79.7 & 81 & 68.6 \\
\hline
\end{tabular}

analysis of these five sequences demonstrated the occurrence of two Trichostrongylus species infection in the studied individuals. Among the representative sequences, KF204573 and KF204574 belonged to Trichostrongylus axei (100\% similarity), while the remaining sequences (i.e., KF204575, KF204576 and KF204577) were identified as Trichostrongylus colubriformis with $98-100 \%$ similarity to the published sequences in GenBank (Table 2). In goats, T. colubriformis (75 of 79 or $94.9 \%$ ) was more predominant than T. axei (4 of 79 or $5.1 \%$ ). In contrast, only T. axei ( 2 of 2 or $100 \%$ ) was detected in deer. Overall, in goats, the infection rate of $H$. contortus was $58.6 \%$ (92 of 157) followed by $T$. colubriformis $(47.8 \%$ or 75 of 157) and T. axei (2.5\% or 4 of 157$)$. With regards to deer, T. axei (2.9\% or 2 of 70$)$ reported higher infection rate than H. contortus ( $1.4 \%$ or 1 of 70$)$.

With regards to single parasitic infection, in goats, single $H$. contortus infection (17 of 157 or $10.8 \%$ ) exhibited the highest infection rate, followed by $T$. colubriformis (4 of 157 or $2.5 \%$ ) and T. axei (1 of 157 or $0.6 \%$ ). Moreover, mono-parasitism was also detected in deer. Among the strongylid positive individuals, co-infections of both strongylid species (HTC denoting $H$. contortus $+T$. colubriformis infections; HTA denoting $H$. contortus $+T$. axei infections), HTC and HTA infections were only observed in goats, with HTC infections (71 of 157 or $45.2 \%$ ) being more predominant than HTA (3 of 157 or 1.9\%) (Table 3). As for deer, no poly-parasitism (double infections) was found in the present study.

\section{Discussion}

In Malaysia, the molecular detection of parasites of veterinary importance in livestock such as Giardia [16], Cryptosporidium [17,18], Neospora caninum [19] have been reported. However, there is a conspicuous lack of molecular data focusing on strongylid parasites, the most pathogenic group of GIP to livestock in Malaysia. In the present study, the most common strongylid parasite, $H$. contortus infection was found in $22.4 \%$ (93 of 416) of studied animals, comprising 92 goats (58.6\% of 157) and one deer (1.4\% of 70$)$. A number of drug resistance studies in Malaysia have indicated that $H$. contortus remains the most widespread strongylid species (73-97\%) in small ruminants (i.e., goats and sheep) [20-23]. These studies have indirectly acknowledged the preponderance of $H$. contortus infection in Malaysia and the current study further confirms this notion. Likewise, the predominance of this parasite species in goats has been reported worldwide. In comparison with previous studies, the prevalence of strongylids noted in this study was much lower than Kenya (90\%) [24], Zimbabwe (88-97\%) [25] and Brazil (96.9\%) [26].

In contrast, $H$. contortus was less common among the studied domesticated deer. Similar findings were also noted in the red deer in Stelvio National Park, one of the main protected areas of north-eastern Italy (1.3\%) [27] and roe deer in the northwest of Iberian Peninsula, Spain (1.4\%) [28]. The results indicated this species might not be a major threat to the wellness of deer [27]. Nonetheless, this

Table 2 Haemonchus contortus, Trichostrongylus colubriformis and Trichostrongylus axei in livestock fecal samples (microscopically strongylid positive) determined by DNA sequencing and Neighbor-Joining analysis according to type of livestock

\begin{tabular}{|c|c|c|c|c|c|c|c|c|}
\hline \multirow[t]{3}{*}{ Livestock } & \multirow{3}{*}{$\begin{array}{l}\text { PCR positive } \\
\text { (primer HAE } \\
\text { and NC2) }\end{array}$} & \multirow{2}{*}{\multicolumn{2}{|c|}{ H. contortus* }} & \multirow{3}{*}{$\begin{array}{l}\text { PCR positive } \\
\text { (primer TRI } \\
\text { and NC2) }\end{array}$} & \multicolumn{4}{|c|}{ Trichostrongylus spp. } \\
\hline & & & & & \multicolumn{2}{|c|}{ T. colubriformis* } & \multicolumn{2}{|c|}{ T. axei* } \\
\hline & & No. & $\%$ & & No. & $\%$ & No. & $\%$ \\
\hline Deer & 1 & 1 & 100.0 & 2 & 0 & 0 & 2 & 100.0 \\
\hline Goat & 93 & 92 & 98.9 & 79 & 75 & 94.9 & 4 & 5.1 \\
\hline Total & 94 & 93 & 98.9 & 81 & 75 & 92.6 & 6 & 7.4 \\
\hline
\end{tabular}

*Species identity confirmed by Neighbour-Joining Analysis. 


\begin{tabular}{|c|c|c|c|c|}
\hline \multirow[t]{2}{*}{ Parasitism } & \multicolumn{2}{|c|}{ Deer } & \multicolumn{2}{|c|}{ Goat } \\
\hline & No. & $\%$ & No. & $\%$ \\
\hline \multicolumn{5}{|l|}{ Single infection } \\
\hline H. contortus & 1 & 1.4 & 17 & 10.8 \\
\hline T. colubriformis & 0 & 0 & 4 & 2.5 \\
\hline T. axei & 2 & 2.9 & 1 & 0.6 \\
\hline \multicolumn{5}{|l|}{ Co-infection } \\
\hline H.contortus+T. colubriformis & 0 & 0 & 71 & 45.2 \\
\hline H. contortus+T. axei & 0 & 0 & 3 & 1.9 \\
\hline
\end{tabular}

finding must not be generalized and a more comprehensive study in the country should be conducted.

Trichostrongylus infection was also observed in the present study. Although Trichostrongylus is less significant to livestock compared to $H$. contortus, its impact on livestock cannot be underestimated [5,29]. In Malaysia, a series of drug resistance studies reported that Trichostrongylus (5-26\%) was the second predominant strongylid parasite species among livestock after $H$. contortus (73-97\%) [20-23]. In recent years, there is an increasing trend of Trichostrongylus infection in small ruminants (personal communication, Veterinary Research Institute, Malaysia). Not surprisingly, more than half of the strongylid infected goats and deer in the present study were positive for Trichostrongylus. Among the Trichostrongylus species, T. colubriformis was the most common species in goats. The infection of small ruminants with this species appears to be common with a wide spectrum of prevalence rates, as high as $78-100 \%$ in Nigeria [30,31], more than $90 \%$ in France [32] and as low as $9.8 \%$ in Iran [33]. Apart from small ruminants, T. colubriformis infection has also been reported in other livestock including cattle $[5,29,34]$. However, none of the Trichostrongylus species was detected among cattle samples in the present study.

As for $T$. axei, its predomination in temperate zones around the world have been pointed out [35], such as Nigeria (69.2\%) [31], Australia (overall more than 90\%) [36] and Zimbabwe (88-97\%) [25]. However, in Malaysia (a tropical country), there is only one study reporting that T. axei was the most common strongylid parasite as observed from post-mortem examination of small ruminants [37]. This is in contrast with the findings of the present study, where a very low frequency of $T$. axei was demonstrated. It is important to point out that the current status of T. axei in Malaysia remains unknown and therefore pinpoints the need for additional concerted research efforts in future.

Based on the results, none of the cattle and swine samples were positive for $H$. contortus and Trichostrongylus spp. Generally, Haemonchus placei, Cooperia pectinata, Cooperia punctate and Ostertagia spp. were the dominant strongylid parasites in cattle, notably in Kenya and Netherlands [38-40]. Attempts to amplify these species using the primer sets of Gasser et al. [9] were made but no positive samples found in the present study (unpublished data). Interestingly, the canine specific hookworm species (Ancylostoma caninum) was detected in one of the cattle sample in the present study as confirmed by DNA sequencing (data not shown). There is a high possibility of the cattle being a mechanical transporter. However, the actual factor(s) that contribute to this rare case need to be further investigated.

With regards to swine, absence of $H$. contortus, $T$. axei and $T$. colubriformis was observed among current studied swine samples. Although the occasional existence of $T$. axei has been described [5,29], its prevalence remained low $(<5 \%)[41]$ and less significant to swine. As compared to $T$. axei, T. colubriformis is more common in swine where the natural incidental infections of $T$. colubriformis have been reported in Hungary, Australia, Russia and United Kingdom [42]. However, little attention has been paid to gastrointestinal parasitic infections in swine in Malaysia. It is crucial that a comprehensive coverage of the current status of parasitic infections in swine populations in Malaysia is conducted in future.

Even though there have been a number of publications stating co-infections of strongylid in animals [29,30], limited scientific reports demonstrated the real situation within host especially Malaysian livestock. The present study demonstrated that co-infections with $H$. contortus and T. colubriformis were predominant in goats. Fakae and Chiejina [30] have reported the co-occurrence of these strongylids (i.e., $H$. contortus and T. colubriformis) in goats ranging from $90 \%$ to $100 \%$, which was significantly higher than the present study. With regards to co-existence of $H$. contortus and $T$. axei in goats, only a low number of strongylid positive samples were observed. Given the limited information currently available regarding the Malaysian $T$. axei, this result is crucial in filling the gap of knowledge of parasitic infection among ruminants in Malaysia.

Co-infection between $H$. contortus or $T$. colubriformis with other gastrointestinal parasites in small ruminants has been reported. Among these two strongylid species, T. colubriformis commonly co-occurred with other GIP to produce a more severe impact compared to single infection to the host. For example, Ostertagia circumcincta co-infected with $T$. colubriformis has been shown to significantly reduce wool growth in lambs (up to 66\%) [43] while Eimeria spp. and T. colubriformis infections resulted in enteritis [29]. As for $H$. contortus, severe impacts (i.e., inappetence, severe scouring, and reduction in live body weight and death) have also been demonstrated during co-infection with Eimeria spp. [44]. 
With regards to co-infection of $H$. contortus or $T$. colubriformis, a series of studies reported the significant association between milk production and co-occurrence of these two strongylid species in dairy goats, which caused the reduction in milk yields (13.0-25.1\%) in goats with highest milk production at the initial stage of the study [45]. In addition, Chartier and Hoste [46] found that repeated exposure to the mixture of $H$. contortus and T. colubriformis caused goats with high milk production to suffer more severe pathophysiological disturbances (increase in pepsinogen concentration and decrease in inorganic phosphate concentrations) and severe depression in milk yields $(-8--35 \%)$. Given that the severe pathophysiology and productivity attributable to the coinfection of gastrointestinal parasites, the current results suggest the strongylids co-infected individuals might also suffer with similar impact of this phenomenon. Therefore, there is now an urgent need to investigate the co-infection status of strongylid parasites among Malaysian livestock for better treatment management.

\section{Conclusions}

In summary, the present study is the first molecular identification of strongylid among Malaysian livestock which is essential for an in-depth understanding of the epidemiology of gastro-intestinal parasitic infection status in Malaysia. The findings of this study revealed the high infection rate of $H$. contortus in goats followed by $T$. colubriformis and $T$. axei with the co-existence of $H$. contortus and Trichostrongylus spp. infections in goats. Indeed, a comprehensive research such as nationwide investigation of GIP prevalence among livestock by the application of genotyping tools should be carried out in the near future. In addition, the authors would like to propose that the Malaysian government via its agency (i.e., Department of Veterinary Services) and research institute (Veterinary Research Institute) utilize the molecular screening tools for strongylid species identification. The accurate data will be very useful in some area such as the mapping in Geographical Information System (GIS) to determine the infection status, prevalence, distribution of strongylid parasites among the livestock in Malaysia. Also, to evaluate the future trends of strongylid infections among livestock in order to formulate more effective disease control programmes and worm management in Malaysia.

\section{Methods}

\section{Ethical consideration}

The study protocol was approved by the Ethics Committee of the University Malaya Medical Center, Malaysia (MEC Ref. No. 896.36). Permission for the study to be conducted on animal farms was obtained from owners prior to sample collection.

\section{Scatological procedure and fecal sample collection}

The scatological survey was carried out in five farms located in three states in Malaysia, namely Selangor (Farm A in Serdang district), Perak (Farm B in Kuala Kangsar district; and Farm D in Batang Padang district) and Sarawak (Farm C and Farm E in Bau district). Among the farms studied, Farm A and Farm B reared more than two species of livestock (i.e., cattle, deer and goats). These animals are reared separately and speculated to have the lowest possibility of cross-GIP transmission. Goats were raised in Farms A, B and C, whereas, swine were raised in Farms D and E. The swine were raised under intensive farming while goats were kept in semi intensive management whereby they grazed in pastures during the day and housed in sheds at night. On the other hand, cattle and deer at farms A and B were managed extensively whereby they were allowed to graze in the fields or pastures. The age of the livestock ranged from 3 months to 3.5 years -in goats, 5 months to 9 years in cattle, 6 to 8 months in swine, and an average of 2 years in deer. All the studied farms were routinely monitored by the Department of Veterinary Services, Malaysia.

Fecal samples were collected per rectum from the animals studied. The fecal samples were tightly sealed in plastic bags and stored at $2^{\circ} \mathrm{C}$ to $8^{\circ} \mathrm{C}$ immediately after collection. Samples were transferred to laboratory and stored at $-20^{\circ} \mathrm{C}$ until further analysis. The collected samples were processed by the formalin-ether concentration technique [47], followed by microscopic screening aided by Lugol's iodine stain. The examination was performed using the 10X objective of a compound microscope for detection of GIP ova. The samples which were microscopically positive for strongylid eggs were further characterized by using genotyping tools.

\section{DNA isolation}

The samples that were microscopically positive for strongylids were subjected to DNA extraction by using the QIAamp ${ }^{\circledR}$ DNA Stool Mini Kit (Qiagen, Germany) according to the manufacturer's prescribed protocol. Approximately $200 \mathrm{mg}$ of fecal sample was used for DNA extraction. Firm feces (i.e., goat and deer fecal pellets) were mechanically homogenized prior to DNA isolation following the manufacturer's instructions. An additional step was taken during stool lysis; whereby silica beads were added to the fecal samples in a $2 \mathrm{ml}$ centrifuge tube with $1.4 \mathrm{ml}$ ASL buffer, followed by 10 minutes of horizontal vortexing with a vortex adapter (catalog no. 1300-V1; MO BIO Laboratories, Carlsbad, $\mathrm{CA})$ before proceeding to incubation at $70^{\circ} \mathrm{C}$ for $10 \mathrm{mi}$ nutes. A concentrated $50 \mu \mathrm{l}$ of DNA was eluted and subsequently stored at $-20^{\circ} \mathrm{C}$ prior to molecular genotyping of strongylid species. 


\section{PCR amplification}

A single step PCR was conducted to amplify the region of the second internal transcribed spacer (ITS2) of nuclear ribosomal DNA (rDNA) of the strongylid species (i.e., H. contortus and Trichostrongylus sp.). The amplifications were aided by two different pairs of primers in separate reactions and each reaction consisted of a species specific forward primer and a universal reverse primer for strongylid species. As for $H$. contortus, a product of $265 \mathrm{bp}$ was amplified using the forward primer HAE (5'-CAA ATG GCA TTT GTC TTT TAG-3') and the reverse primer NC2 $\left(5^{\prime}\right.$-TTA GTT TCT TTT CCT CCG CT-3') [12]; as for Trichostrongylus spp., a product of 267-268 bp was amplified by the forward primer TRI ( $5^{\prime}$-TCG AAT GGT CAT TGT CAA- ${ }^{\prime}$ ) and the reverse primer NC2 [12]. Precautions were taken to prevent contamination at every step of the procedure [i.e., PCR preparation was conducted in laminar flow cabinet, exposure of ultraviolet radiation (UV) on apparatus (micropipettes) and consumables (glove, micropipette tips, $1.5 \mathrm{ml}$ and $200 \mu \mathrm{l}$ tubes), separate rooms for DNA extraction and PCR etc.]. Each PCR was performed in a $50 \mu \mathrm{l}$ reaction containing 10× PCR buffer, $2.5 \mathrm{mM}$ dNTPs, $25 \mathrm{mM}$ $\mathrm{MgCl}_{2}, 10 \mathrm{pmol}$ of each forward and reverse primer, 5 units of Taq polymerase and $6 \mu \mathrm{l}$ of DNA template [48]. Negative (without DNA; replaced by nuclease free water) and positives (with DNA template of H. contortus and Trichostrongylus sp.) were also included in each PCR run. The PCR was carried out in the Bio-rad MyCyler ${ }^{\mathrm{Tm}}$ Thermal Cycler Serial Number: 580BR 7200 (CA, USA). The cycling programme included $94^{\circ} \mathrm{C}$ for $5 \mathrm{~min}$ (initial denaturation), followed by 35 cycles of $94^{\circ} \mathrm{C}$ for $30 \mathrm{~s}$ (denaturation), $55^{\circ} \mathrm{C}$ for $30 \mathrm{~s}$ (annealing), $72^{\circ} \mathrm{C}$ for $30 \mathrm{~s}$ (extension), and a final extension at $72^{\circ} \mathrm{C}$ for $7 \mathrm{~min}$ [12].

\section{Sequence analysis and strongylid species identification}

All the PCR amplified fragments were purified by QIAquick PCR Purification Kit (QIAGEN, Germany) according to manufacturer's prescribed protocol prior to DNA sequencing. The purified PCR products were subjected to bidirectional DNA sequencing using the ABI PRISM 1 BigDyeTM Terminator v3.0 Ready Reaction Cycle Sequence Kit (Applied Biosystems, USA) in a 3700 DNA Analyzer (Applied Biosystems, USA). The obtained sequence chromatograms were viewed using Sequence Scanner 1.0 (Applied Biosystems, Foster City, CA). The sequence data were analyzed and preliminary aligned with the published reference sequences of H. contortus (KF36428-KF36432, HQ6837 10-HQ683715, FN432335-FN432336, JN12897-JN12898, JQ342246-JQ342247, X78803), H. placei (KF364623-KF3 64627, JN128895-JN128896, JQ342248-JQ342249, X78812) as presented in Jabbar et al. [49]; T. axei (KC998724KC998727, AY439026) and T. colubriformis (AB503241-
AB503243, AB503246, AB503250, AB503252, HQ844229) using BioEdit 7.0.9.0. [50]. The species identity was confirmed by Neighbor-Joining analysis using MEGA4 [51]. The Neighbour-Joining bootstrap values were estimated using 1000 replicates with Kimura's two-parameter model of substitution (K2P distance) evolution model.

\section{Competing interests}

The authors declare that they have no competing interests.

\section{Authors' contributions}

TKT research design, conduct research, data analysis, manuscript preparation; $\mathrm{CP}$ manuscript revision; VLL conduct research, manuscript revision; $\mathrm{SCL}$ conduct research; RN conduct research; RSKS research design, manuscript revision; YALL project leader, research design, manuscript revision. All authors read and approved the final manuscript.

\section{Acknowledgements}

The authors thank the farmers and director of Infoternak farm, Kuala Kangsar, Perak for their collaborative efforts. This study was supported by University of Malaya grants PV024/2011B, RG221/10HTM, H-20001-00-E000061.

\section{Author details}

${ }^{1}$ Department of Parasitology, Faculty of Medicine, University of Malaya, 50603 Kuala Lumpur, Malaysia. ${ }^{2}$ Veterinary Research Institute, 59, Jalan Sultan Azlan Shah, 31400 Ipoh, Perak, Malaysia. ${ }^{3}$ Institute of Biological Sciences, Faculty of Science, University of Malaya, 50603 Kuala Lumpur, Malaysia. ${ }^{4}$ Department of Veterinary Laboratory Diagnosis, Faculty of Veterinary Medicine, Universiti Putra Malaysia, 43400 UPM Serdang, Selangor, Malaysia.

Received: 15 July 2013 Accepted: 28 January 2014

Published: 7 February 2014

\section{References}

1. Zajac AM: Gastrointestinal nematodes of small ruminants: life cycle, anthelmintics, and Diagnosis. Vet Clin Food Anim 2006, 22:529-541.

2. Getachew T, Dorchies $P$, Jacquiet $P$ : Trends and challenges in the effective and sustainable control of Haemonchus contortus infection in sheep. Review. Parasite 2007, 14:3-14.

3. Simpson HV: Pathophysiology of abomasal parasitism: is the host or parasite responsible? Vet J 2000, 2000(160):177-191.

4. Angulo-Cubillán FJ, García-Coiradas L, Cuquerella M, Fuente CDL, Alunda JM: Haemonchus contortus-sheep relationship: a review. Revista Científica 2007, 17:577-587.

5. Taylor MA, Coop RL, Wall RL: Veterinary Parasitology. 3rd edition. Oxford: Blackwell Publishing Ltd; 2007.

6. Holmes PH: Pathogenesis of trichostrongylosis. Vet Parasitol 1985, 18:89-101.

7. Vlassoff A: Seasonal incidence of infective trichostrongyle larvae on pasture grazed by lambs. New Zeal J Exp Agr 1973, 1973:1

8. Agyei AD: Seasonal changes in the level of infective strongylate nematode larvae on pasture in the coastal savanna regions of Ghana. Vet Parasitol 1997, 70:175-182.

9. Gasser RB, Chilton NB, Hoste H, Beveridge I: Rapid sequencing of rDNA from single worms and eggs of parasitic helminths. Nucleic Acids Res 1993, 21:2525-2526.

10. Gasser RB, Rossi L, Zhu X: Identification of Nematodirus species (Nematoda: Molineidae) from wild ruminants in Italy using ribosomal DNA markers. Int J Parasitol 1999, 29:1809-1817.

11. Dallas JF, Irvine RJ, Halvorsen O, Albon SD: Identification by polymerase chain reaction (PCR) of Marshallagia marshalli and Ostertagia gruehneri from Svalbard reindeer. Int J Parasitol 2000, 30:863-866.

12. Bott NJ, Campbell BE, Beveridge I, Chilton NB, Rees D, Hunt PW, Gasser RB: A combined microscopic-molecular method for the diagnosis of strongylid infections in sheep. Int J Parasitol 2009, 39:1277-1287.

13. Gharamah AA, SitiAzizah MN, Rahman WA: Genetic variation of Haemonchus contortus (Trichostrongylidae) in sheep and goats from Malaysia and Yemen. Vet Parasitol 2012, 188:268-276.

14. Hoste H, Chilton NB, Gasser RB, Beveridge I: Differences in the second internal transcribed spacer (ribosomal DNA) between five species of 
Trichostrongylus (Nematoda: Trichostrongyloidae). Int J Parasitol 1995, 25:75-80.

15. Heise M, Epe C, Schnieder T: Differences in the second internal transcribed spacer (ITS-2) of eight species of gastrointestinal nematodes of ruminants. J Parasitol 1999, 85:431-435.

16. Lim YAL, Mahdy MAK, Tan TK, Goh XT, Jex AR, Nolan MJ, Sharma RSK, Gasser RB: First molecular characterization of Giardia duodenalis from goats in Malaysia. Mol Cell Probes 2013, 27:28-31.

17. Abdul Halim N, Plutzer J, Bakheit MA, Karanis P: First report of Cryptosporidium deer-like genotype in Malaysian cattle. Vet Parasitol 2008, 152:325-329.

18. Muhid A, Robertson I, Ng J, Ryan U: Prevalence of and management factors contributing to Cryptosporidium sp. infection in pre-weaned and post-weaned calves in Johor, Malaysia. Exp Parasitol 2011, 127:534-538.

19. Cheah TS, Mattsson JG, Zaini M, Sani RA, Jakubek EB, Uggla A, Chandrawathani P: Isolation of Neospora caninum from a calf in Malaysia. Vet Parasitol 2004, 126:263-269.

20. Basripuzi HB, Sani RA, Ariff OM: Anthelmintic resistance in selected goat farms in Kelantan. Mal J Anim Sci 2012, 15:47-56.

21. Chandrawathani $P, A d n a n$ M, Waller PJ: Anthelmintic resistance in sheep and goats farms on Peninsular Malaysia. Vet Parasitol 1999, 82:305-310.

22. Chandrawathani P, Waller PJ, Adnan M, Höglund J: Evolution of high-level, multiple anthelmintic resistance on a sheep farm in Malaysia. Trop Anim Health Pro 2003, 2003(35):17-25.

23. Khadijah $S$, Rahman WA, Chandrawathani P, Waller PJ, Vasuge M, Nurulaini R, Adnan M, Jamnah O, Zaini CM, Vincent N: Nematode anthelmintic resistance on government small ruminant farms in Peninsular Malaysia. Jurnal Veterinar Malaysia 2006, 18:1-5.

24. Gatongi PM, Prichard RK, Ranjan S, Gathuma JM, Munyua WK, Cheruiyot H, Scott ME: Hypobiosis of Haemonchus contortus in natural infections of sheep and goats in a semi-arid area of Kenya. Vet Parasitol 1998, 77:49-61.

25. Pandey VS, Ndao M, Kumar V: Seasonal prevalence of gastrointestinal nematodes in communal land goats from the Highveld of Zimbabwe. Vet Parasitol 1994, 51:241-248.

26. Charles TP: Seasonal prevalence of gastrointestinal nematodes of goats in Pernambuco state, Brazil. Vet Parasitol 1989, 30:335-343.

27. Manfredi MT, Di Cerbo AR, Tranquillo V, Nassuato C, Pedrotti L, Piccolo G: Abomasal nematodes of the red deer Cervus elaphus in north-eastern Italy. J Helminthol 2007, 81:247-253.

28. Pato FJ, Vázquez L, Díez-Baños N, López C, Sánchez-Andrade R, Fernández G, Díez-Baños P, Díaz P, Morrondo P: Gastrointestinal nematode infections in roe deer (Capreolus capreolus) from the NW of the Iberian Peninsula: assessment of some rick factors. Vet Parasitol. In press.

29. Kaufmann J: Parasitic infections of domestic animals: a diagnostic manual. Basel, Germany: BirkhäuserVerlag; 1996.

30. Fakae BB, Chiejina SN: The prevalence of concurrent trypanosome and gastrointestinal nematode infections in West African Dwaf sheep and goats in Nsukka area of eastern Nigeria. Vet Parasitol 1993, 49:313-318.

31. Nwosu CO, Ogunrinade AF, Fagbemi BO: Prevalence and seasonal changes in the gastro-intestinal helminthes of Nigerian goats. $J$ Helminthol 1996, 70:329-333.

32. Chartier C, Reche B: Gastrointestinal helminthes and lungworms of French dairy goats: prevalence and geographical distribution in Poitou-Charentes. Vet Res Commun 1992, 16:327-335.

33. Shahbazi A, Fallah E, Koshki MHK, Nematollahi A, Chazanchaei A, Asfaram S: Morphological characterization of the Trichostrongylus species isolated from sheep in Tabriz, Iran. Res Opin Anim Vet Sci 2012, 2:309-312.

34. Aumont G, Gauthier D, Coulaud G, Gruner L: Gastro-intestinal parasitism of cattle in native pasture grazing system in Guadeloupe (French West Indies). Vet Parasitol 1991, 40:29-46.

35. Fox MT: Gastrointestinal parasites in sheep and goats. The Merck Veterinary Manual. http://www.merckmanuals.com/vet/digestive_system/ gastrointestinal_parasites_of_ruminants/gastrointestinal_parasites_of_sheep_ and_goats.html.

36. Craig BH, Pilkingston JG, Pemberton JM: Gastrointestinal nematode species burdens and host mortality in a feral sheep population. Parasitology 2006, 133:485-496.

37. Amin-Babjee SM: 1993. Parasitic diseases of domestic ruminants in Malaysia. In The Animal Industry in Malaysia. 1st edition. Edited by Fatimah CTNI, Ramlah AH, Bahaman AR. Malaysia: Faculty of Veterinary Medicine and Animal Science: Universiti Pertanian; 1993:179-185.
38. Waruiru RM, Nansen P, Kyvsgaard NC, Thamsborg SM, Munyua WK, Gathuma JM, Bøgh HO: An abattoir survey of gastrointestinal nematode infections in cattle in the central highlands of Kenya. Vet Res Commun 1998, 22:325-334.

39. Waruiru RM, Thamsborg SM, Nansen P, Kyvsgaard NC, Bogh HO, Munyua WK, Gathuma JM: The epidemiology of gastrointestinal nematodes of dairy cettle in central Kenya. Trop Anim Health Pro 2001, 33:173-187.

40. Borgsteede FHM, Tibben J, Cornelissen JBWJ, Agneessens J, Gaasenbeek $\mathrm{CPH}$ : Nematode parasites of adult dairy cattle in the Netherlands. Vet Parasitol 2000, 89:287-296.

41. Nganga CJ, Karanja DN, Mutune MN: The prevalence of gastrointestinal helminth infections in pigs in Kenya. Trop Anim Health Pro 2008, 40:331-334

42. Knight RA: Natural infection of sheep nematode, Trichostrongylus colubriformis, in Mississippi swine, and differences in specimens from sheep and swine. J Parasitol 1968, 54:635-637.

43. Steel JW, Jones WO, Symons LEA: Effects of a concurrent infection of Trichostrongylus colubriformis on the productivity with physiological and metabolic responses of lambs infected with Ostertagia circumcincta. Aust J Agr Sci 1982, 1982(33):131-140.

44. Abakar AD, El Amin EA, Osman AY: The interaction of Coccidian and Haemonchus contortus infections in desert lambs. The Sudan J Vet Res 2001, 17:15-26.

45. Hoste $H$, Chartier $\mathrm{C}$ : Comparison of the effects on milk production of concurrent infection with Haemonchus contortus and Trichostrongylus colubriformis in high- and low- producing dairy goats. Am J Vet Res 1993 54:1886-1893.

46. Chartier $\mathrm{C}$, Hoste $\mathrm{H}$ : Response to challenge infection with Haemonchus contortus and Trichostrongylus colubriformis in dairy goats differences between high and low-producers. Vet Parasitol 1997, 73:267-276.

47. Allen AV, Ridley DS: Further observations on the formol-ether concentration technique for faecal parasites. J Clin Pathol 1970, 23:545-546.

48. Ngui R, Lee SC, Tan TK, Muhammad Aidil R, Lim YAL: Molecular identification of human hookworm infections in economically disadvantaged communities in Peninsular Malaysia. Am J Trop Med Hyg 2012, 86:837-842.

49. Jabbar A, Cotter J, Lyon J, Koehler AV, Gasser RB, Besier B: Unexpected occurrence of Haemonchus placei in cattle in southern Western Australia. Infect Genet Evol 2014, 21:252-258.

50. Hall TA: BioEdit: a user friendly biological sequence alignment editor and analysis program for Windows 95/98/NT. Nucleic Acids Symp Ser 1999, 1999(41):95-98.

51. Tamura K, Dudley J, Nei M, Kumar S: MEGA4: Molecular Evolutionary Genetics Analysis (MEGA) software version 4.0. Mol Biol Evol 2007, 24:1596-1599.

doi:10.1186/1746-6148-10-38

Cite this article as: Tan et al:: Co-infection of Haemonchus contortus and Trichostrongylus spp. among livestock in Malaysia as revealed by amplification and sequencing of the internal transcribed spacer II DNA region. BMC Veterinary Research 2014 10:38.

\section{Submit your next manuscript to BioMed Central and take full advantage of:}

- Convenient online submission

- Thorough peer review

- No space constraints or color figure charges

- Immediate publication on acceptance

- Inclusion in PubMed, CAS, Scopus and Google Scholar

- Research which is freely available for redistribution 